\title{
Consórcio de espécies arbóreas com leguminosas herbáceas como estratégia para restauraçãoflorestal
}

\author{
Flávio Augusto Monteiro dos Santos ${ }^{1}$ Paulo Sérgio dos Santos Leles ${ }^{1}$ João Elves da Silva Santana ${ }^{1}$ Juçara Garcia Ribeiro $^{1}$ Alexander Silva de Resende ${ }^{2}$ \\ ${ }^{1}$ Universidade Federal Rural do Rio de Janeiro, Instituto de Florestas, BR 465, km7, Seropédica - RJ, CEP 23890-000 \\ ${ }^{2}$ Embrapa Agrobiologia. Rodovia BR-465, Km 7 - Ecologia, Seropédica - RJ, 23890-000 \\ *Author for correspondence: joao.elvis.santana@gmail.com \\ Received: June 2018 / Accepted: March 2019 / Published: June 2019
}

\section{Resumo}

Objetivou-se avaliar o consórcio de espécies arbóreas com leguminosas herbáceas como estratégia de controle de gramíneas em área de restauração florestal. Utilizou-se duas estratégias: tratamento mecânico, que consistiu de capinas em faixas de 1,2 $\mathrm{m}$ de largura nas linhas de plantio e roçadas nas entrelinhas de plantio, sempre que a vegetação infestante atingiu $35 \mathrm{~cm}$ de parte aérea, e o tratamento cultural, em que foi realizada uma capina em área total e em seguida a semeadura de leguminosas herbáceas nas entrelinhas das espécies arbóreas. Avaliou-se o crescimento em altura aos 6, $12,18,24$ e 30 meses após o plantio, o diâmetro ao nível do solo e cobertura do solo pelas copas aos 30 meses de 10 espécies arbóreas. Também se quantificou a massa de matéria seca de gramíneas aos 25 meses após plantio das plantas arbóreas. Em todas as épocas de avaliação, em média, as dez espécies arbóreas obtiveram crescimento em altura significativamente superior no tratamento em que houve o consórcio com leguminosas (Cultural), mesmo comportamento observado para diâmetro ao nível do solo e cobertura de copa aos 30 meses. Na unidade do tratamento mecânico a infestação de gramíneas, aos 25 meses após o plantio, foi cerca de 3,5 vezes maior ao observado no tratamento Cultural. Conclui-se que o consórcio com leguminosas herbáceas facilitou o crescimento das espécies arbóreas no período avaliado, por promover sombreamento do solo, dificultando o crescimento das plantas espontâneas.

Palavras-chave: Controle de plantas espontâneas; adubação verde e recuperação da Mata Atlântica.

\section{Abstract}

This study aimed to evaluate tree species intercropped with herbaceous legumes on formation of forest restoration stands. The treatments consisted of two weed control methods: mechanical weeding in $1.2 \mathrm{~m}$ bands in the planting row and mowing in between rows, whenever necessary, and mechanical/cultural with total area weeding, followed by sowing herbaceous legumes planting in between rows. Ten tree species were planted with spacing of $3.2 \mathrm{~m} \mathrm{x} 1.7 \mathrm{~m}$, in 15 rows of ten plants per treatment. Three herbaceous legume species were sown and cropped, initially, Crotalaria juncea alone, followed by Canavalia ensiformis and Cajanus cajan. The growth of tree species were evaluated at 6, 12, 18, 24 and 30 months after planting. In the last evaluation, it was also measured tree diameter at soil level, canopy cover area and content quantification of soil macronutrients and organic matter. All the ten tree species in the intercropped treatment have had significantly superior growth in height, diameter at soil level and canopy cover, in mean terms. This study shows that herbaceous legumes intercropped with tree species have had positive effects in the growth of the trees during evaluated period.

Keywords: Weed control; green manure and Atlantic forest restoration.

\section{Introdução}

O histórico de degradação do bioma Mata Atlântica ocasionou redução da oferta de serviços ecossistêmicos em uma das regiões mais populosas do Brasil, e com isso têm motivado a adoção de políticas públicas de incentivo à restauração de ecossistemas florestais. Considerado um processo de larga escala de tempo e com alto custo envolvido, a restauração florestal se consolida como campo para a investigação científica, sendo propostas estratégias para acelerar este processo (Rech et al. 2015), como por exemplo, o plantio de espécies arbóreas nativas que facilita a sucessão natural (Marcuzzo et al. 2015).

Devido a fatores como a presença de plantas indesejadas e a baixa fertilidade dos solos (Klippel et al. 2015) a restauração em ambientes tropicais, como a Mata Atlântica, apresenta várias dificuldades. Segundo Calegari et al. (2013) em locais com dominância de espécies do gênero Urochloa (braquiárias) a restauração florestal é dificultada, devido a agressividade das plantas deste gênero.

No estado do Rio de Janeiro a maioria das áreas destinadas à restauração florestal encontram-se descaracterizadas do ponto de vista da composição de espécies nativas, sendo representados em sua maior parte por pastagens em diferentes estágios de degradação, em que predominam espécies de gramíneas agressivas (Resende e Leles 2017). A alta habilidade competitiva dessas espécies de gramíneas (Pereira et al. 2014), como as braquiárias, aliado ao crescimento lento de espécies arbóreas nativas, exige a adoção de estratégias de controle eficientes, que maximizem o sucesso da formação dos povoamentos florestais. Segundo Leles et al. (2015), o controle das plantas espontâneas pode representar até $60 \%$ dos custos de formação de povoamentos para restauração florestal, evidenciando a necessidade de medidas de controle eficientes.

Dentre as alternativas de controle de plantas espontâneas na formação de povoamentos de restauração florestal, o consórcio com espécies leguminosas herbáceas fixadoras de nitrogênio vem sendo objeto de alguns estudos (César et al. 2013; Lemessa e Wakjira 2015). Isernhagen et al. (2014) mencionam que esta prática se fundamenta no cultivo de espécies que apresentam vantagens competitivas em relação às plantas infestantes locais, reduzindo sua população, ajudando a recuperação dos solos e beneficiando, em última instância, as plantas das espécies florestais. Segundo Amoghein et al. (2013) e Santos et al. (2013), as leguminosas herbáceas de rápido crescimento promovem a cobertura do solo, reduzindo a densidade das plantas espontâneas e favorecendo o estabelecimento e o crescimento das plantas arbóreas implantadas.

Além da supressão das plantas espontâneas, o cultivo dessas espécies pode melhorar as condições do solo. São plantas que apresentam cobertura vegetal capaz de aumentar o teor de matéria orgânica do solo, a concentração de nutrientes perto da superfície e atenuar processos erosivos (Akingbola e 
Dayo-Olagbende 2017). Também contribuem diretamente para a diminuição da temperatura e manutenção da umidade do solo (Silva et al. 2016).

O controle de plantas espontâneas em plantios de restauração florestal normalmente está baseado na utilização de técnicas mecânicas como a capina e a roçada. Tendo em vista as limitações desse método de controle e os potenciais benefícios do consórcio de espécies leguminosas herbáceas com o povoamento de restauração florestal, o objetivo desse estudo foi avaliar o emprego de leguminosas herbáceas como estratégia no controle de plantas espontâneas para formação de povoamentos de restauração florestal em comparação ao controle tradicional de roçada e coroamento.

\section{Material e métodos \\ Caracterização da região e da área experimental}

$\mathrm{O}$ experimento foi conduzido durante 30 meses (novembro de 2011 a abril de 2014), no município de Bom Jardim, região serrana do estado do Rio de Janeiro, em área pertencente à Pequena Central Hidrelétrica (PCH) Santa Rosa II, localizada nas coordenadas $22^{\circ} 7^{\prime} 21,78^{\prime \prime} \mathrm{S}$ e $42^{\circ} 18^{\prime} 33,95^{\prime \prime} \mathrm{O}$. A altitude média da região é de $530 \mathrm{~m}$.

O clima do município é do tipo Aw (verão chuvoso e inverno seco), segundo a classificação de Köppen. Com base em dados da estação de Cordeiro - RJ, a mais próxima da área experimental, fornecidos pelo Instituto Nacional de Meteorologia (INMET 2014), no período de janeiro de 2011 a dezembro de 2014, a precipitação média anual foi de 1.184 $\mathrm{mm}$, sendo que $76,5 \%$ desta precipitação ocorreu entre os meses de novembro a março. Nos meses de julho, agosto e setembro praticamente não ocorreram chuvas na região. A temperatura média anual no período do experimento, foi de $21,1{ }^{\circ} \mathrm{C}$, com média de mínima de $15,6{ }^{\circ} \mathrm{C}$ no mês de julho e média de máxima de $29,4^{\circ} \mathrm{C}$, no mês de fevereiro.

O local do experimento apresenta declividade média de $25^{\circ}$. Antes da implantação do experimento, a área era utilizada como pastagem, onde predominavam espécies de braquiária, principalmente Urochloa brizantha (Stapf) Webster cv. Marandu e $U$. decumbens (Stapf.) Webster. O solo da área foi classificado como Latossolo Vermelho Amarelo Distrófico, com as seguintes características químicas na camada de $0-20$ $\mathrm{cm}: \mathrm{pH}=4,9 ; \mathrm{P}=0,7 \mathrm{mg} \mathrm{dm}^{-3} ; \mathrm{K}=18 \mathrm{mg} \mathrm{dm}^{-3} ; \mathrm{Al}^{3+}=1,0$; $\mathrm{Ca}^{2+}=0,2 \mathrm{e} \mathrm{Mg}^{2+}=0,1 \mathrm{cmol}_{\mathrm{c}} \mathrm{dm}^{-3}$.

\section{Caracterização do experimento}

Foram empregados dois tratamentos, que consistiram de estratégias de controle das plantas espontâneas, sendo estes: tratamento 1 (controle mecânico) - capina em faixas de 1,2 m de largura nas linhas de plantio das espécies arbóreas e roçadas nas entrelinhas, sempre que o capim braquiária atingiu altura média de $35 \mathrm{~cm}$. A primeira roçada ocorreu 70 dias após o plantio. No tratamento 2 (controle cultural) foi realizada capinada com enxada em área total aos 70 dias após o plantio das espécies arbóreas, e em seguida foi realizada a semeadura da leguminosa herbácea Crotalaria juncea L. (crotalária). No final do ciclo de produção, a crotalária foi roçada e, em seguida, foi realizada semeadura de Canavalia ensiformis DC. (feijão-de-porco) e Cajanus cajan L. Milssp. (feijão-guandu), nas entrelinhas das plantas das espécies arbóreas.

Foram alocadas duas unidades amostrais, totalizando $1.640 \mathrm{~m}^{2}$, nas quais avaliou-se as duas estratégias de controle das plantas espontâneas: controle mecânico e o consórcio com leguminosas. Cada unidade experimental foi formada por 15 plantas de 10 espécies arbóreas, com uma planta de cada espécie por linha de plantio, totalizando 15 linhas de plantio (150 plantas) dispostas numa área de $820 \mathrm{~m}^{2}$. A sequência de distribuição das mudas nas covas de plantio em cada linha foi a mesma em ambas as unidades.

Antes do plantio, toda a área foi roçada com roçadeira lateral. Após esta etapa foram abertos os berços de plantio, com dimensões de $30 \mathrm{~cm}$ x $30 \mathrm{~cm}$ x $30 \mathrm{~cm}$ (largura, comprimento e profundidade), e estes foram adubados com 120 gramas de N-P-K (03-24-04) + 15,0\% Ca + 4,7\% S, sendo $18 \% \quad \mathrm{P}_{2} \mathrm{O}_{5}$ solúvel em ácido cítrico. Em seguida, realizou-se o plantio das mudas das espécies arbóreas, que ocorreu na primeira semana de novembro (período chuvoso) de 2011, adotando o espaçamento $3,2 \mathrm{~m} \times 1,7 \mathrm{~m}$. Todas as atividades foram realizadas manualmente.

Foram utilizadas mudas produzidas em sacos plásticos de $9 \mathrm{~cm}$ x $20 \mathrm{~cm}$ (diâmetro x altura), de dez espécies arbóreas, comumente utilizadas em projetos de restauração florestal da Mata Atlântica, do estado do Rio de Janeiro: Anadenanthera macrocarpa (Benth.) Brenan) - angico-vermelho; Cordia trichotoma (Vell.) Arrab. ex Steud.) - louro-pardo; Cytharexyllum myrianthum Cham.- pau-viola, Enterolobium contortisiliquum (Vell.) - orelha-de-macaco; Guarea guidonia (L.) Sleumer - carrapeta; Peltophorum dubim (Springer.) Taub. - farinha-seca; Schinus terebinthifolius Raddi. - aroeirapimenteira; Schizolobium parahyba (Vell.) S.F. Blake guapuruvu, Senna multijuga (Rich.) Irwin et Barn. - paucigarra e Tibouchina granulosa Cogn., - Quaresmeira.

Para a semeadura da crotalária, foram abertos sulcos de 5 $\mathrm{cm}$ de profundidade, distanciados entre si por $50 \mathrm{~cm}$, entre as linhas de semeadura. Os sulcos próximos a linha de plantio das plantas arbóreas, ficaram distantes $60 \mathrm{~cm}$ destas. Assim, foram 5 linhas de sulcos de crotalária. Em cada metro linear de sulco foram semeadas em torno de 10 sementes de crotalária.

Para semeadura do feijão-guandu, no início da estação chuvosa na região, no meio da entrelinha de plantio das espécies arbóreas foi aberto um sulco de $5 \mathrm{~cm}$ de profundidade e realizada a semeadura com 12 sementes por metro linear. No mesmo dia, entre este sulco de semeadura do guandu e a linha das espécies arbóreas, foram abertas pequenas covas distanciadas entre si por aproximadamente $45 \mathrm{~cm}$ e realizou-se semeadura de feijão-de-porco, sendo colocadas duas sementes por cova. As épocas das operações de semeadura, cultivo e roçada/poda das leguminosas herbáceas estão descritas na Figura 1, assim como as atividades de manutenção do tratamento Mecânico.

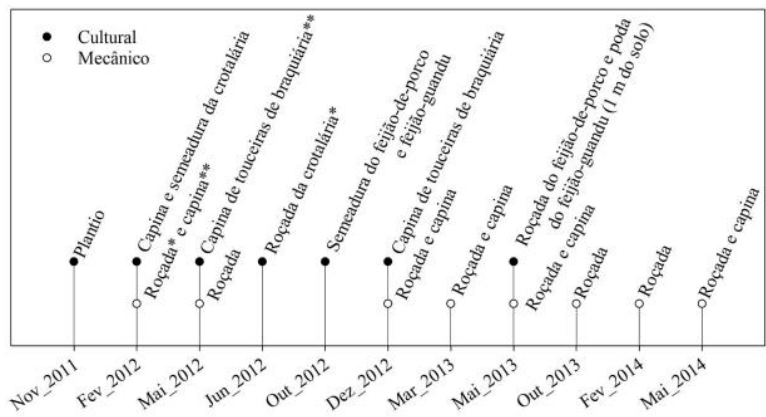

Figura 1: Atividades de manutenção realizadas, por época, em duas estratégias de controle de plantas espontâneas para formação de reflorestamento para restauração florestal, no município de Bom Jardim, RJ. * Com roçadeira lateral ** com enxada.

O controle das formigas cortadeiras iniciou-se 40 dias antes do plantio e ocorreu rotineiramente, utilizando iscas granuladas. Replantio foi realizado aos 40 dias, utilizando indivíduos da mesma espécie. Adubações de cobertura 
Santos et al.

ocorreram aos 6 e 12 meses após o plantio, com aplicação de 50 e 100 gramas de N-P-K (20-05-20) por planta, respectivamente.

\section{Avaliações}

Foram realizadas avaliações de crescimento em altura, aos $6,12,18,24$ e 30 meses após o plantio. Também aos 30 meses foram realizadas avaliações de sobrevivência (\%), diâmetro ao nível do solo, com uso de paquímetro digital, e comprimento de copa longitudinal $\left(D_{1}\right)$ e transversal à linha de plantio $\left(D_{2}\right)$, com auxílio de trena.

Com os dados de comprimento de copa, determinou-se a área da projeção da copa (ai) e a cobertura do solo pela projeção perpendicular da copa das espécies arbóreas implantadas, aplicando-se os métodos de grau de cobertura (GC) (Müeller-Dombois e Ellemberg 1974) e intercessão de linhas (IL) (Canfield 1941), a partir das seguintes equações: - Área da projeção da copa de cada indivíduo $\left(\mathrm{m}^{2}\right)$ :

- Grau de cobertura $(\%)$ :

$$
a_{i}=\left(\frac{\pi * D_{1} * D_{2}}{4}\right)
$$

-Intersecção de linhas (\%):

$$
G C=\left(\frac{\sum a_{i}}{A}\right) * 100
$$

$$
I L=\left(\frac{\Sigma D_{1}}{C}\right)
$$

Em que:

$A=$ área da parcela $\left(\mathrm{m}^{2}\right)$;

$C=$ comprimento da linha de plantio (m).

Aos 25 meses após o plantio (dezembro de 2013 - época chuvosa) foi realizada avaliação da biomassa da parte aérea de braquiária em ambos os tratamentos. Para isto, em cada unidade experimental, foram alocados aleatoriamente 15 gabaritos de $1 \mathrm{~m} \times 1 \mathrm{~m}$ e toda a parte aérea de braquiária foi cortada rente ao solo e coletada.

Após coleta, o material foi separado em laboratório, deixando apenas a braquiária, colocado em sacos de papel e levados para estufa de circulação de ar, para secar a $65^{\circ} \mathrm{C}$, durante 72 horas, obtendo-se o peso de matéria seca da parte aérea de braquiária.

Aos 30 meses foram retiradas, aleatoriamente, quatro amostras de solo, da camada de $0-20 \mathrm{~cm}$ de profundidade, em cada tratamento. Em laboratório, as oito amostras de terra foram destorroadas e seca ao ar e encaminhadas para laboratório para análise de teores de macronutrientes e de matéria orgânica.

\section{Análises estatísticas}

Os dados de altura (nas diferentes idades), diâmetro ao nível do solo, grau de cobertura do solo, a massa de matéria seca de braquiária e os teores de macronutrientes e matéria orgânica, foram submetidos ao teste $\mathrm{t}$ de amostras independentes, adotando nível de significância de 95\%. Para as análises foi utilizado o software Sistema de Análise Estatística e Genética (SAEG).

\section{Resultados e discussão}

Aos 30 meses após o plantio, as taxas de sobrevivência foram de $89,3 \%$ e 93,8\%, para os tratamentos Mecânico e Cultural, respectivamente. Apenas para duas espécies os valores de sobrevivência foram abaixo de $80 \%$, C. trichotoma - 61,1 \% (Mecânico) e 72,5\% e G. guidonia - 76,2\% no tratamento Cultural. Ambas, além dos menores valores de sobrevivência, apresentaram também o menor crescimento em altura (Tabela 1) e em diâmetro ao nível do solo, aos 30 meses após o plantio (Figura 2A). Acredita-se que alguns fatores como a intensificação da competição por luz, água e nutrientes entre os indivíduos arbóreos espaçados de $1,7 \mathrm{~m}$ por planta, podem ser apontados como possível explicação para que algumas espécies apresentem taxa de sobrevivência abaixo de $80 \%$.

O crescimento em altura, do conjunto formado pelas dez espécies florestais implantadas, foi significativamente superior nas unidades experimentais que receberam o consórcio com leguminosas herbáceas (Tabela 1). Este comportamento foi observado desde a primeira avaliação, aos seis meses após o plantio, até a última avaliação. Em média, aos 30 meses, o crescimento em altura das plantas do tratamento consorciado foi $68,4 \%$ superior ao tratamento de controle mecânico.

A. macrocarpa, S. multijuga, E. contortisiliquum, P. dubim e $S$. parahyba foram as espécies que apresentaram maior crescimento em todas as idades avaliadas. Todas apresentaram crescimento significativamente superior no tratamento consorciado, com exceção de E. contortisiliquum.

Tabela 1: Altura (m) de dez espécies arbóreas implantadas para restauração florestal em cinco idades após o plantio, em resposta a duas estratégias de controle de plantas espontâneas, em área de

\begin{tabular}{|c|c|c|c|c|c|c|c|c|c|}
\hline \multirow{3}{*}{ Espécie } & \multicolumn{9}{|c|}{ Altura das plantas (m) } \\
\hline & \multicolumn{3}{|c|}{-6 meses - -12 meses - } & \multicolumn{2}{|c|}{-18 meses - } & \multicolumn{2}{|c|}{-24 meses - } & \multicolumn{2}{|c|}{-30 meses - } \\
\hline & $\mathrm{Tl}$ & $\begin{array}{l:ll}\mathrm{T} 2 & \mathrm{~T} 1\end{array}$ & $\mathrm{~T} 2$ & $\mathrm{Tl}$ & T2 & $\mathrm{T} 1$ & $\mathrm{~T} 2$ & $\mathrm{~T} 1$ & $\mathrm{~T} 2$ \\
\hline A. macrocarpa & 0,8 & $\begin{array}{l:ll}1,2^{*} & 1,0 \\
\end{array}$ & $1,5^{*}$ & 1,5 & $2,7^{*}$ & 1,7 & $3,1^{*}$ & 2,7 & $4,0^{*}$ \\
\hline C. trichotoma & 0,5 & $\begin{array}{l:l}0,8^{*} & 0,6\end{array}$ & $1,2 *$ & 0,6 & $1,6^{*}$ & 0,6 & $1,7^{*}$ & 1,0 & $2,1 *$ \\
\hline C. myrianthum & 0,4 & $0,8^{*}: 0,5$ & $1,3^{*}$ & 0,9 & $2,5^{*}$ & 0,9 & $2,7 *$ & 1,6 & $2,9 *$ \\
\hline E. contortisiliquum & 1,4 & $\begin{array}{l:l}1,7^{\mathrm{ns}} & 1,7\end{array}$ & $2,2 *$ & 2,0 & $2,6^{\mathrm{ns}}$ & 2,1 & $2,9^{*}$ & 2,7 & $3,2^{2 \mathrm{~ns}}$ \\
\hline G. Guidonia & 0,6 & $0,7^{\text {ns }}: 0,7$ & $0,9^{\text {ns }}$ & 0,7 & $1,1^{\mathrm{ns}}$ & 0,7 & $1,3 *$ & 1,2 & $1,8^{*}$ \\
\hline P. dubim & 0,5 & $\begin{array}{l:l}1,3 * 8 & 0,8\end{array}$ & $1,9 *$ & 1,1 & $2,9^{*}$ & 1,3 & $3,1^{*}$ & 1,7 & $3,6^{*}$ \\
\hline S. terebinthifolius & 0,7 & $\begin{array}{l:l}0,9^{\text {ns }} & 0,8\end{array}$ & $1,2^{*}$ & 1,1 & $2,0^{*}$ & 1,2 & $2,2^{*}$ & 1,9 & $2,8^{*}$ \\
\hline S. parahyba & 0,7 & $\begin{array}{l:l}1,5^{*} & 0,9 \\
\end{array}$ & $2,4 *$ & 1,1 & $3,7^{*}$ & 1,1 & $4,3^{*}$ & 1,8 & $5,2^{*}$ \\
\hline S. multijuga & 0,8 & $1,4^{*}: 1,0$ & $2,1 *$ & 1,2 & $2,8^{*}$ & 1,3 & $3,2^{*}$ & 2,1 & $3,9 *$ \\
\hline T. granulosa & 0,8 & $\begin{array}{l:l}1,0^{\text {ns }} & 0,9\end{array}$ & $1,3^{*}$ & 1,1 & $2,0^{*}$ & 1,4 & $2,1^{*}$ & 2,0 & $2,8^{*}$ \\
\hline Média & 0,7 & $\begin{array}{l}1,1^{*} \\
\end{array}$ & $1,6^{*}$ & 1,1 & $2,4^{*}$ & 1,2 & $2,8^{*}$ & 1,9 & $3,2^{*}$ \\
\hline
\end{tabular}
reflorestamento, localizada no município de Bom Jardim, RJ. T1 controle mecânico; T2 -controle cultural

* Diferença significativa a $5 \%$ pelo teste $\mathrm{t}$ de amostras independentes; ${ }^{\mathrm{n}}$ Diferença não significativa a $5 \%$ pelo teste $t$ de amostras independentes.

Ao analisar os valores médios de diâmetro ao nível do solo (Figura 2A) e o grau de cobertura do solo (Figura 2B), constatou-se a mesma tendência de crescimento em altura, na qual as plantas arbóreas apresentaram, em média, crescimento significativamente superior quando em consórcio com as leguminosas. A cobertura por copas no tratamento consorciado foi superior a $90 \%$ em área e a $100 \%$ na linha de plantio (Figura 2B). Isto indica que, aos 30 meses após o plantio, grande parte da superfície do solo estava sombreada pelas copas das plantas arbóreas, o que reduz a presença das plantas de braquiária. Nesse tratamento há ainda a cobertura oferecida pelas espécies leguminosas, mantidas na área no período entre dois e dez meses após o plantio das arbóreas (crotalária) e de 11 a 30 meses, pelo feijão-de-porco e guandu. 


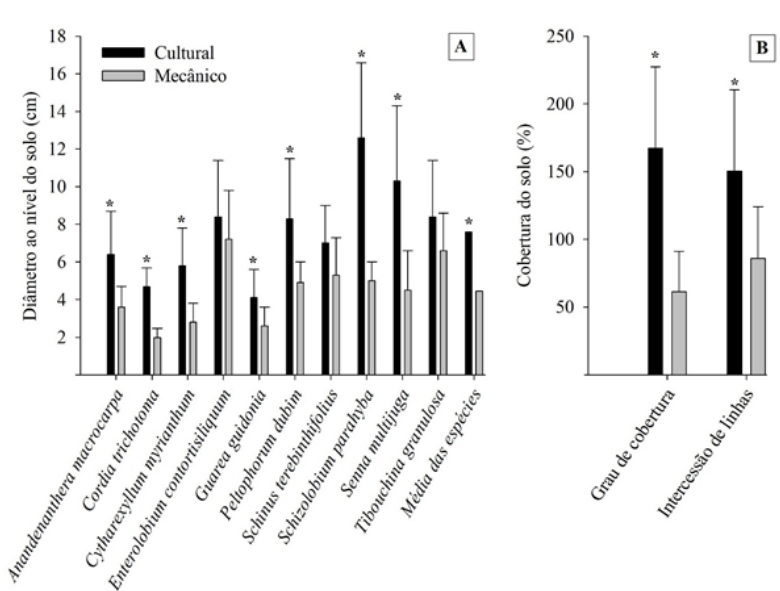

Figura 2: Crescimento (média e desvio padrão) do conjunto das dez espécies arbóreas implantadas, 30 meses após o plantio, em resposta a duas estratégias de controle de plantas espontâneas em área de reflorestamento, no município de Bom Jardim, RJ. A - Diâmetro ao nível do solo; B - Cobertura do solo pela copa segundo os métodos do "Grau de cobertura" e "Intercessão de linhas". *Tratamentos diferem entre si a $5 \%$ pelo teste $\mathrm{t}$ de amostras independentes.

Essa tendência de maior crescimento no tratamento consorciado não esteve ligada a alterações da fertilidade do solo, pois não houve diferença significativa no teor de macronutrientes e matéria orgânica entre os dois tratamentos, na camada de solo $0-20 \mathrm{~cm}$, aos 30 meses após o plantio (Tabela 2). Comparando os dados da Tabela 2 com os dados de fertilidade antes do plantio, observa-se que praticamente não houve diferenças na fertilidade do solo, indicando que o tempo de avaliação foi curto para que se pudesse identificar alterações das características químicas do solo. Longo et al. (2011), avaliando diferentes estratégias para recuperação da fertilidade de solos degradados por mineração no estado de Rondônia, observaram que a utilização de adubos verdes (Cajanus cajans e Mucuna aterrima) não provocou incremento da matéria orgânica no solo, aos 15 meses após a semeadura das mesmas. Segundo os autores, é necessário maior tempo para que as alterações nos teores de matéria orgânica na camada superficial do solo possam ser detectadas.

Tabela 2: Análise química de amostras de solos, naprofundidade de 0 $20 \mathrm{~cm}$, sob duas estratégias de controle de plantas espontâneas, aos 30 meses após o plantio das mudas arbóreas, em área de reflorestamento, município de Bom Jardim, RJ

\begin{tabular}{|c|c|c|c|c|c|c|c|c|}
\hline \multirow{2}{*}{ Tratamento } & \multirow{2}{*}{$\mathrm{pH}$} & $\mathrm{P}$ & $\mathrm{K}^{+}$ & $\mathrm{Ca}^{2+}$ & $\mathrm{Mg}^{2+}$ & $\mathrm{AP}^{\beta^{+}}$ & MO & P-rem \\
\hline & & \multicolumn{2}{|c|}{$---\mathrm{mg} \mathrm{dm}^{3}-\cdots$} & 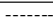 & molc dn & --1- & dag $\mathrm{kg}^{-1}$ & $\mathrm{mg} \mathrm{L}^{-1}$ \\
\hline Legumino: & 4,9 & 0,5 & 11,7 & 0,22 & 0,19 & 1,20 & 2,71 & 15,63 \\
\hline Roçada & 4,8 & 1,1 & 20,7 & 0,34 & 0,11 & 1,17 & 2,76 & 16,43 \\
\hline
\end{tabular}

$\mathrm{p} \overline{\mathrm{H} \text { em água; } \mathrm{P} \text { e K: Extrator Mehlich-1; } \mathrm{Ca}, \mathrm{Mg} \mathrm{e} \mathrm{Al} \mathrm{:} \mathrm{Extrator} \mathrm{KCl}-1 \mathrm{~mol} / \mathrm{L}}$; Mat. Org. (MO) - Oxidação: $\mathrm{Na}_{2} \mathrm{Cr}_{2} \mathrm{O}_{7} 4 \mathrm{~N}+\mathrm{H}_{2} \mathrm{SO}_{4} 10 \mathrm{~N}$; P-rem = Fósforo remanescente. Os tratamentos não diferem entre si a $5 \%$ pelo teste t de amostras independentes.

Provavelmente um dos fatores que favoreceu o maior crescimento das espécies arbóreas em consórcio com as leguminosas foi o efeito da cobertura dessas espécies em atenuar a chegada de luz na superfície do solo (Santos et al. 2013), dificultando a sobrevivência das espécies gramíneas sensíveis ao sombreamento. A avaliação de biomassa de braquiária realizada aos 25 meses após o plantio das mudas das espécies arbóreas, revelou valor médio de 261,3 gramas $\mathrm{m}^{-}$ $2(\mathrm{CV}=44,4 \%)$ na área de controle com roçada, enquanto que no consórcio com leguminosas a massa de matéria seca da parte aérea foi de 75,5 gramas $\mathrm{m}^{-2}(\mathrm{CV}=99,0 \%)$. O menor valor médio e a grande variação entre os pontos de coleta indicam que a área que recebeu o consórcio com leguminosas (Cultural) estava bastante descaracterizada quanto a vegetação infestante original, que era dominada por espécies de braquiária, apresentando menor infestação.

Nesse estudo, a Canavalia ensiformis apresentou um rápido crescimento na área experimental, o que possivelmente contribuiu para a interceptação da radiação luminosa que chega ao solo, dificultando a germinação das sementes e o crescimento inicial de plantas de braquiária. Além disso, existem relatos da ação de efeito alelopático de leguminosas de cobertura utilizadas no presente estudo, como a $C$. ensiformis (Monquero et al. 2009) e também de C. juncea (Timossi et al. 2011), sobre espécies de braquiária.

Outro efeito que pode ter contribuído para melhores condições para as espécies arbóreas é a maior umidade do solo, que pode ser proporcionada pela cobertura do solo pelas leguminosas em consórcio. Silva et al. (2016) observaram que a cobertura das espécies herbáceas e a deposição de folhas senescentes aumentam a proteção do solo contra a luz solar direta, aliviando as temperaturas e diminuindo a amplitude térmica, o que implica na menor evapotranspiração e maior umidade do solo. É possível que após a roçada da crotalária, colheita do feijão-de-porco e poda do feijão-guandu tenham ocorrido esses benefícios, contribuindo para o maior crescimento das espécies arbóreas consorciadas.

Diante dos resultados obtidos é possível inferir que o cultivo de espécies leguminosas facilitou o estabelecimento das espécies florestais nativas, tendo em vista o seu maior crescimento quando em consórcio. Com isso, constatou-se que este consórcio tem potencial na formação dos povoamentos para restauração florestal, sendo necessários maior número de estudos, principalmente envolvendo custos e aprimoramento da técnica.

\section{Conclusões}

O consórcio com leguminosas herbáceas proporcionou maior crescimento das plantas arbóreas aos 30 meses após o plantio, quando comparado ao controle mecânico, com roçadas e capinas. Também promoveu menor infestação de gramíneas aos 25 meses após implantação do povoamento.

Os resultados indicam que consórcio com leguminosas herbáceas pode diminuir o tempo de formação dos povoamentos com espécies arbóreas da Mata Atlântica, quando comparado ao controle mecânico, sendo possível diminuir os custos da restauração florestal. Nesse sentido, é importante $o$ aumento de estudos que avaliem novas estratégias de manejo das leguminosas e o desempenho destas em outras condições edafoclimáticas.

\section{Agradecimentos}

À PCH Santa Rosa S/A por ceder a área, apoio e mão de obra para realização do trabalho.

\section{Referências}

Akingbola OO, Dayo-Olagbende GO (2017) Green manuring to a better soil physical condition. Agricultural Research \& Technology, 11(3):1-2. 10.19080/ARTOAJ.2017.11.555813

Amoghein MB, Tobeh A, Gholipouri A, Jamaati-e-Somarin S, Ghasemi M (2013) Effect of cover crop in control of weed density and some qualitative and quantitative characteristics of sunflower. International Journal of Agriculture and Crop Sciences, 5(12):1318-1323.

Calegari L, Martins SV, Campos LC, Silva E, Gleriani JM (2013) Avaliação do banco de sementes do solo para fins de 
Santos et al.

restauracão florestal em Carandaí, MG. Revista Árvore, 37(5):871-880. doi: http://dx.doi.org/10.1590/S0100$\underline{67622013000500009}$

Canfield RH (1941) Application of the line interception methodin sampling range vegetation. Journal of Forestry, 39(4):388-394. doi: https://doi.org/10.1093/jof/39.4.388

César RG, Brancalion PHS, Rodrigues RR, Oliveira AMS, Alves MC (2013) Does crotalaria (Crotalaria breviflora) or pumpkin (Cucurbita moschata) inter-row cultivation in restoration plantings control invasive grasses? Scientia $\begin{array}{lll}\text { Agricola, } & 70(4): 268-273 . & \text { doi: }\end{array}$ http://dx.doi.org/10.1590/S0103-90162013000400008

Isernhagen I, Bracalion PHS, Rodrigues RR (2014) Adubação verde na restauração florestal. In: Lima Filho OF, Ambrosano EJ, Rossi F, Carlos JAD (Org). Adubação verde e plantas de cobertura no Brasil: fundamentos e prática. Brasília: Embrapa, p.271-287.

Instituto Nacional de Meteorologia (INMET). Estações e dados. Disponível em: < http ://www.inmet.gov.br/portal/index.php ?r=agrometeorologia /balancoHidricoCl64imatico> Acesso em: 19 jan. 2016.

Leles, PSS; Oliveira Neto, SN; Alonso, JM (2015) Restauração florestal em diferentes espaçamentos. In: Leles PSS, Oliveira Neto SN (Org.). Restauração florestal e a Bacia do Rio Guandu. Seropédica: Editora Rural, p.101-153.

Lemessa F, Wakjira M (2017) Cover crops as a means of ecological weed management in agroecosystems. Journal of Crop Science and Biotechnology, 18(2):133-145. doi: 10.1007/s12892-014-0085-2

Klippel VH, Pezzopane JEM, Silva GF, Caldeira MVW, Pimenta LR., Toledo JV (2015) Avaliação de métodos de restauração florestal de Mata de Tabuleiros-ES. Revista Árvore, 39(1):69-79. doi: http://dx.doi.org/10.1590/0100$\underline{67622015000100007}$

Longo RM, Ribeiro AI, Melo WJ (2011) Uso da adubação verde na recuperação de solos degradados por mineração na floresta amazônica. Bragantia, 70(1):139-146. doi: http://dx.doi.org/10.1590/S0006-87052011000100020

Marcuzzo SB, Araújo MM, Gasparin E (2015) Plantio de espécies nativas para restauração de áreas em Unidades de Conservação: um estudo de caso no sul do Brasil. Floresta, 45(1):129-140. doi: http://dx.doi.org/10.5380/rf.v45i1.32763

Melo ACG, Miranda DLC, Durigan G (2007) Cobertura de copas como indicador de desenvolvimento estrutural de reflorestamentos de restauração de matas ciliares no médio vale do Paranapanema, SP, Brasil. Revista Árvore, 31(2):321$328 . \quad$ doi: http://dx.doi.org/10.1590/S0100$\underline{67622007000200015}$

Monquero PA, Amaral LR, Inácio EM, Brunhara JP, Binha DP, Silva PV, Silva AC (2009) Efeito de adubos verdes na supressão de espécies de plantas daninhas. Planta Daninha, 27(1): $\quad 85-95$. doi: http://dx.doi.org/10.1590/S0100$\underline{83582009000100012}$

Mueller-Dombois D, Ellenberg H (1974) Aims and methods of vegetation ecology. New York: John Wiley and Sons. 547p.

Pereira FCM, Barroso AAM, Albrecht AJP, Alves PLCA (2014) Interferência de plantas infestantes: conceitos e exemplos na cultura do eucalipto. Journal of Agronomic Sciences, 3(1):236-255.
Rech CCC, Silva AC, Higuchi P, Schimalski MB, Pscheidt F, Schmidt AB, Ansolin RD, Bento MA, Missio FF, Loebens R (2015) Avaliação da restauração florestal de uma APP degradada em Santa Catarina. Floresta e Ambiente, 22(2):194203. doi: http://dx.doi.org/10.1590/2179-8087.083414.

Resende AS, Leles PSS (2017) O problema do controle de plantas daninhas na restauração florestal. In: Resende AS, Leles PSS (Org.). Controle de plantas daninhas em restauração florestal. Brasília: Embrapa, p.13-27.

Santos JCF, Cunha AJ, Ferreira FA, Santos RHS, Sakiyama NS, Lima PC (2013) Cultivation of perennial herbaceous legumes in weed management in coffee plantation on the Cerrado. Journal of Agricultural Science and Technology, 3(6):420-428

Silva DMN, Oliveira FL, Teodoro RB, Fávero C, Quaresma MAL (2016) Temperature and humidity of soil covered with perennial herbaceous legumes in the semiarid region of Minas Gerais state, Brazil. Bioscience Journal, 32(1):11-19. doi: 10.14393/BJ-v32n1a2016-26241

Timossi PC, Wisintainer C, Santos BJ, Pereira VA, Porto VS (2011) Supressão de plantas daninhas e produção de sementes de crotalária, em função de métodos de semeadura. Pesquisa Agropecuária Tropical, 41(4):525-530. doi: http://dx.doi.org/10.5216/pat.v41i4.11603 